\title{
Research on the Path of Structural Reform of Agricultural Supply Side
}

\author{
Yu He ${ }^{1}$, Wenkuan Chen ${ }^{1}$ \\ ${ }^{1}$ Sichuan Agricultural University, Chengdu, Sichuan, 611130
}

Keywords: Agriculture, supply-side reform, industrial integration

\begin{abstract}
From the 19th to the 20th of the party, it is the historical convergence period of the "two hundred years" struggle goal, winning the victory to build a well-off society in an all-round way, and building a socialist modernization power. Agriculture, rural peasants and the agricultural supply side structural reform cannot fall behind. It must be continued and the path of advancement must be feasible and effective. Based on the practice, this paper proposes the promotion path of the agricultural supply side structural reform from three aspects: overall industrial layout, promotion of agricultural multi-functional development, and construction of industrial alliance.
\end{abstract}

\section{Introduction}

The supply-side structural reform should proceed from the improvement of supply quality, adopt reforms to promote structural adjustment, correct distortions in factor allocation, expand effective supply, improve the adaptability and flexibility of supply structure to demand changes, and improve total factor productivity and better meet The needs of the broad masses of the people will promote the sustained and healthy development of the social economy. For a big country with more than 1.3 billion people, agriculture plays a pivotal role and value. At present, agriculture is still a short-term "synchronization of the four modernizations". The focus of agricultural reform is on the supply-side structural reform, and the difficulty is also on the supply side.

\section{Coordinating the layout of the agricultural industry across the province and realizing the layout of regulations}

(1) Prioritize the layout of agricultural basic industries that can achieve food supply security. According to the population level of each region, the grain demand in the region is measured, and then the grain planting area is calculated according to the grain yield level. It is strictly forbidden for the non-grain industry to occupy permanent basic farmland, especially paddy fields.

(2) Layout of new business forms in the agricultural industry. Enrich the industrial organization form, at the same time, lay out the industrial functions, perfect the small and medium-sized comprehensive industries and the specialized large-scale industries with close integration of upstream and downstream agricultural production, and give play to the advantages of "comprehensive" and "chain-type" agricultural industrial organizations; support agricultural products processing, logistics, etc. The supporting service industry relies on the original production base of agriculture to select the processing logistics industry layout that is close to the production area and has convenient transportation locations.

(3) Realize the dynamic adjustment of industrial layout. The development of agricultural economy is a dynamic process. The layout of each specific agricultural industry should follow the law of industrial structure change and reserve space for the adjustment of agricultural industrial structure. While preventing the external economic shock of the agricultural industry, it will guide the flow of social capital to the agricultural sector and provide space for the external resources of the agricultural industry. Especially when the urbanization development squeezes the development space of the agricultural industry, the agricultural industry layout must achieve the goal of achieving a smooth scale adjustment of the agricultural industry.

1) Improve the implementation of relevant plans for the agricultural industry and improve the level of convergence between different levels and different types of planning. According to the 
environmental endowment of agricultural production resources and the needs of their own social and economic development, rationally and scientifically formulate the detailed layout of the spatial layout of the agricultural industry, delineate the red line of the layout, delineate the functional areas of the agricultural main body, determine the scope of use of the land, and implement the map and implement Go to the ground and make an announcement to develop a regional access and use transfer license system. According to the layout of the agricultural industry, each functional department shall have specific authority to plan and manage the regional space within its respective scope of responsibility, and implement the requirements for use control.

2) Accelerate the establishment of a power constraint mechanism for agricultural industry layout. From the initial link of the industrial layout--the planning and preparation process to maintain the fairness of the allocation of social resources, timely stop the relevant staff or leading cadres to use their powers to "strish the ball and walk the riverside", profit for relatives or others, and strictly do the relevant industries. The confidentiality management of the confidentiality period in which the layout is located, relevant conferences, manuscripts, videos, audio recordings, pictures and other materials must be collected in accordance with the regulations. The staff who violate the relevant regulations of the planning and layout shall be dealt with in a timely manner according to the seriousness of the circumstances.

3) Improve the performance appraisal mechanism for the implementation of the agricultural industry layout, and improve relevant laws and regulations and penalties for violations. Establish a hierarchical evaluation index system for the implementation of agricultural industry layout, and form a "set of measures" including organizational work, working methods, technical paths, coordination mechanisms, safeguard measures, and institutional mechanism reform proposals, and form "regulation of agricultural industries according to law. Implementing the interlocking legalization path of implementing industrial layout and performing evaluation evaluation performance, resolutely prevent and control the mediocre and ruling behavior of some leading cadres to reduce the effectiveness of industrial layout planning and the weakening or overhead control.

(1) Modernization of governance tools. Integrate the construction of a dynamic monitoring information platform for agricultural spatial layout, make full use of observation satellites, agricultural drones and various ground monitoring stations to carry out all-weather monitoring, and timely grasp the changes in the spatial layout of agriculture. Based on the spatial geographic information system to promote the construction of large data on the layout of agricultural industry in Sichuan Province, and timely update and correct its data according to the actual situation, to ensure the real-time and accuracy of data information, to achieve dynamic supervision of the spatial layout of agricultural industry in Sichuan Province.

(2) Modernization of governance technology. Relying on the spatial layout planning of agricultural industries at all levels, a platform for the dissemination of information on the spatial distribution of agricultural industries at the provincial, city, county (district), township (town) and village levels will be established, and an information sharing mechanism will be established. At the same time, according to the modern Internet technology and agricultural Internet of Things technology, the agricultural industry layout information release and the acceptance of the digital platform, the information bridge between the policy makers and the policy implementers, and the transparent and open disclosure of the agricultural industry regional layout information Realize information sharing, and regularly announce and correct non-conformity projects to the public through online and offline platforms.

\section{Promote the multi-functional development of agriculture and rural areas, and stimulate new kinetic energy for rural rejuvenation}

\subsection{Guarantee agricultural supply function}

(1) Effectively provide safe agricultural products and consolidate the foundation of strong agriculture. Encourage qualified localities to promote standardized agricultural production, build a 
number of standardized demonstration bases and safe food production bases, and build a number of national and provincial organic agricultural product certification demonstration zones. Accelerate the formulation of production norms and standards to ensure the quality and safety of agricultural products, promote the implementation of green product standards, certification, and labeling systems, conduct pilot projects for standard evaluation, and establish and improve standard systems covering agricultural production, agricultural management, and agricultural services.

(2) Develop high-quality special agricultural products and innovate individualized agricultural products. The production of bulk agricultural products should focus on high-quality specialization, focusing on the development of high-quality rice and processed forage grass, processed vegetables, forest foods and other special agricultural products. Accelerate the development of high-quality economic forests, wood and bamboo industry raw material forests, woody oil forests and other characteristic forest industries. We will continue to implement the agricultural animal breeding research program and the modern seed industry upgrading project, build a modern seed industry system that promotes breeding and breeding, and promote high-quality special varieties such as corn, rice, wheat, sorghum and livestock.

(3) Strengthening scientific and technological support to lead and improve the quality of agricultural products. With the help of the "Internet + " service, we will improve the information analysis and early warning system for agricultural products, achieve a balance between production and sales, and prevent oversupply of agriculture. Encourage the construction of transshipment and warehousing platform services, shorten the regional spatial distance between production and supply, ensure the timeliness of demand, and actively guide social forces to participate in product processing, warehousing, trading, market and e-commerce platform construction, and promote online Under the development of integration, focus on the development of end distribution.

\subsection{Maintain agricultural ecological functions}

(1) Pay attention to agricultural ecological environment protection and improve resource utilization efficiency. Attention should be paid to the specific functions of dominant microorganisms in agricultural production, to create a modern agricultural system with benign circulation of plants, animals and microorganisms, to reduce the application intensity of pesticides and fertilizers; to promote the fixed-point sales of fertilizers and pesticides, and to advocate formula fertilization. Under the premise of ensuring that the permanent basic farmland is unshakable, organically coordinate the control of cultivated land, garden land, woodland, pasture and other agricultural land, reduce the destructive planning of agricultural land, improve the flood control capacity of agricultural land, and eliminate the use of rural complex. Construction engages in disguised real estate.

(2) Promote agricultural pollution control and strengthen ecosystem restoration. Increase the intensity of rural land pollution control and strengthen the comprehensive management of ecological restoration of contaminated soil. Accelerate the implementation of major projects for the protection and restoration of important ecosystems, promote the comprehensive management of desertification, rocky desertification and soil erosion, implement important wetland protection and restoration projects, properly restore winter paddy fields to increase the area of wetlands, promote the construction of grassland ecological protection zones, and vigorously implement the retreat Projects such as animal husbandry and grassland, severely degraded grassland and grassland disaster prevention and mitigation.

\subsection{Integrate agricultural culture functions}

(1) Actively tap the local characteristics of farming culture and promote the essence of farming culture. Carry out agricultural cultural heritage, general survey of agricultural cultural heritage, traditional villages and general residential censuses, do a good job in organizing and archiving census data, establish a database of protection and inheritance of farming culture, and organize experts to evaluate the value of agricultural cultural heritage of census and clearly protect , inheritance and development priorities. On the basis of clear protection, inheritance and development, we will speed up the rescue and protection of the outstanding cultural heritage of the 
countryside, and display the local characteristic farming culture in a variety of ways, including physical objects, audio-visual images and text albums.

(2) Promote the development of rural cultural industries and create distinctive rural cultural brands. Creatively transforming cultural resources such as red culture, historical culture, national culture, and folk culture to create a rural cultural brand with strong characteristics. Focus on the development of creative and creative ethnic folk culture products, moderate development of rural cultural monuments, and create a unique journey of folk customs, provide reference for the development of folk culture industry, and promote the outstanding brands of rural cultural industry to go out.

\subsection{Promote the integration of the first, second and third industries}

(1) Focus on agricultural products with special advantages and vigorously support the intensive processing of agricultural products. It is necessary to actively promote the development of agricultural and sideline products such as condiments, kimchi, and snack foods, and launch a number of high-quality specialty products that have influence at home and abroad, and strengthen the production and marketing of "Internet + " specialty products to consolidate the national famous agricultural brands. market status.

(2) Rationally allocate rural resources and enhance the core competitiveness of rural tourism. Comprehensive consideration of regional objective factors, integration of land, manpower, capital and other resources, rational layout and accurate positioning according to local actual characteristics, so that rural resources can be maximized. It is necessary to vigorously develop a rural tourism system in which tourism tourism around the city (short-term) and landscape and rural recreational industries (medium and long-term) are coordinated. At the same time, it is necessary to cultivate innovative thinking of practitioners, build a national brand, transform and upgrade traditional famous brands, and try to avoid homogenization.

(3) Strengthen the support of science and technology to improve the quality of the integration of the first, second and third industries. Vigorously develop "Internet $+"$ agriculture, consolidate the development of rural e-commerce, and develop models such as direct supply of agricultural and commercial enterprises, direct sales of origin, short-chain food, community support, member distribution, and personalized customization. By promoting the deep integration of rural one, two, and three industries, we will enhance the comprehensive benefits of the agricultural industry and help build a strong agricultural province.

\section{Integrate resources, build a characteristic, high-quality agricultural industry alliance}

\subsection{Based on the characteristics of advantageous industries, promote the construction of quality alliances}

(1) Integrate the resources of various industries in the industrial chain with standardization as the link, and absorb the new agricultural business entities to join the agricultural industry alliance. Members will jointly formulate the industry regulations and various standards, promote mutual cooperation among members, and give play to the self-discipline of industry. Establish a sound supervision mechanism to encourage fair competition.

(2) Carry out relevant theoretical research work around the industry, adhere to the construction of agricultural theoretical system, organize relevant practices and demonstration activities of the agricultural industry, explore the operational mechanism suitable for the alliance, and research and promote the development model of the alliance.

(3) Break through the cooperation of members, break through the core technologies of common functional agriculture and strengthen the service, transfer and talent cultivation of technology research and development, vigorously develop modern crop seed industry, enlarge and optimize functional agriculture, and promote the synergy innovation capability of this industry. Provide effective technical support for regional agricultural enrichment. 


\subsection{Establish a leadership management organization and establish a lead cooperation unit}

(1) Coordinating and solving problems such as the establishment of the registration of agricultural industry alliances, project funding support, etc., starting from the reality of industry and enterprises, giving full play to the coordination capacity of the government, ensuring that the members of the alliance truly have the willingness to cooperate and create a development that is conducive to the development of the alliance. Policy environment, legal environment and human environment.

(2) Conduct macro guidance on the agricultural industry alliance, maintain close attention to the development of the alliance and implement necessary assessments, take the assessment work as an opportunity to strengthen the dynamic management of the alliance, form a scientific and standardized alliance management mechanism, and let the alliance "spontaneously and voluntarily The principle of "autonomy and autonomy" operates.

(3) Strengthen the classification and guidance of the agricultural industry alliance, give play to the industrial advantages and industry characteristics, promote the self-discipline development of the alliance, and constantly improve and optimize the operation system of the alliance; Fifth, set the priority industrial fields and do a good job in the agricultural industry alliance. The strategic deployment of development reduces the disorderly and blind development of the alliance.

\subsection{Build a policy support system and increase financial support}

From the perspective of equity protection and technical support. The first is to allow and encourage the establishment of a diversified agricultural industry alliance organization form, especially to encourage and vigorously promote the company's legal person-type agricultural industry alliance to solve the problem of alliance legal identity; second, according to the problems and development needs of the agricultural industry alliance, timely relevant The law protects the legitimate rights and interests of the alliance. At the same time, it also regulates the behavior of the franchisees, and increases the punishment for the alliance members to violate the alliance contract behavior, so that the formation and operation of the alliance can be legally enforced. Third, strengthen intellectual property protection and formulate And improve relevant support policies, including science and technology plans, technological advancement, technological innovation, technology introduction, scientific and technological achievements transformation and industrialization policies, etc., and give priority support to the agricultural industry alliance that is in line with regional economic characteristics and is conducive to the integration of advantageous resources. At the same time, through the contract system and corresponding regulations, it provides a legal basis for determining the ownership and use rights of intellectual property rights of the agricultural industry alliance; the fourth is to transfer some government functions and transfer or entrust some functions performed by the original government to the agricultural industry alliance, such as The standards formulated by the Empowered Alliance are recognized by the government, giving the alliance certain powers and appropriate means; the fifth is to encourage university scientific research units to join the agricultural industry alliance, give the technical support of the alliance and undertake special topics related to agricultural research, and promote the talents among the alliance members. The rationalization, free flow and the transformation of scientific research results within the alliance promote the division of labor, resource integration and joint innovation between industry, academia and research.

From the perspective of financial support. First, when establishing a new public finance system, the support funds of the Agricultural Industry Alliance will be included in the budget, and a new mechanism for the development of the financial aid alliance will be established. Second, for the growth enterprises in the agricultural industry alliance, the financial loans will be given interest subsidies. The third is to change the way of relying mainly on scientific research projects to support the agricultural industry alliance, combined with the use of project funding, major achievements rewards, tax reductions and other means to avoid policy rent-seeking as much as possible; fourth, in the industry common technology research and development On the other hand, according to the characteristics of the industry, the government should come forward and use financial funds as a 
guide to organize relevant partners in the agricultural industry alliance to participate, agree on a result-sharing mechanism, and focus on common technologies that restrict industrial development. Fifth, introduce new policy support. The funding needs of the Agricultural Industry Alliance, such as encouraging banks and venture capital institutions to participate in alliances, providing diversified financing support and financial services to alliance enterprises; fifth, supporting the establishment of alliance small enterprise loan companies or alliance development funds within the agricultural industry alliance and other forms, support the alliance Grow.

\section{References}

[1] Luo Biliang. The key, difficult and direction of agricultural supply side reform [J]. Rural Economy, 2017, (01): 1-10.

[2] Zhang Shoukui. Discussion on the Path of Structural Reform of Agricultural Supply Side by the Integration and Development of the First, Second and Third Industries[J]. Theory's Guide,2016,(5):68-71.

[3] Chen Xiwen. On the structural reform of the supply side of agriculture [J]. Journal of China Agricultural University (Social Science Edition), 2017, (02): 5-8. 